\title{
BM Global Health Informal collectives and access to healthcare during India's COVID-19 second wave crisis
}

\author{
Neha Faruqui, ${ }^{1}$ VR Raman, ${ }^{2,3}$ Jeevika Shiv, ${ }^{4}$ Sonam Chaturvedi, ${ }^{5}$ \\ Maitree Muzumdar, ${ }^{6}$ Vandana Prasad (i) ${ }^{7}$
}

To cite: Faruqui N, Raman VR, Shiv J, et al. Informal collectives and access to healthcare during India's COVID-19 second wave crisis. BMJ Global Health 2021;6:e006731. doi:10.1136/ bmjgh-2021-006731

Received 25 June 2021 Accepted 28 June 2021

\section{Check for updates}

(c) Author(s) (or their employer(s)) 2021. Re-use permitted under CC BY-NC. No commercial re-use. See rights and permissions. Published by BMJ.

${ }^{1}$ School of Public Health, University of Sydney, Sydney, New South Wales, Australia ${ }^{2}$ Public Health Resource Network, New Delhi, India ${ }^{3}$ All India People's Science Network, New Delhi, India ${ }^{4}$ Social Worker and Lawyer, New Delhi, India

${ }^{5} \mathrm{OP}$ Jindal Global University, Sonipat, Haryana, India ${ }^{6}$ Independent Filmmaker and Lawyer, Gujarat, India

${ }^{7}$ Public Health Resource Network, Noida, Uttar Pradesh, India

Correspondence to Mr VR Raman;

weareraman@phrnindia.org

\section{BACKGROUND}

India was hit by a disastrous second wave of the COVID-19 pandemic that surged since February 2021. The exact magnitude of cases and deaths during this second wave remains a contentious topic, as suggested by huge differences between internal reports of the government and external reports. ${ }^{12}$ However, there is no dispute that, although several curbing strategies including a harsh lockdown were introduced during the early days of the pandemic in March 2020, the country now finds itself again in the midst of a crisis. Compared with last year, this time the virus has shown a much higher transmissibility rate, possibly due to a combination of newer variants, coupled with poor regulation and adherence to basic preventive public health measures. Mass gatherings in the form of massive election rallies and religious congregations were also permitted while cases had started increasing exponentially in numerous states of India, and vaccination rates continued to remain low.

Health systems in major cities were overwhelmed with cases even in the first wave, where some hospital wards were dedicated to COVID-19 care, non-COVID care was almost halted ${ }^{34}$ and healthcare workers were stretched thin. ${ }^{5}$ The second wave now saw a collapse of the system where not just wards but entire hospitals had to be used and expanded for exclusive COVID-19 care and still remained inadequate. In addition, we witnessed the conversion of maidans (open fields), gurdwaras (Sikh religious institutions) and other places into makeshift wards and hubs for accessing oxygen. The crisis revealed the pre-existing cracks in an underprepared health system where people were left to help themselves, gasping for oxygen or drugs and scrambling for hospital beds. ${ }^{6}$ However, as with any crisis, human beings rise to find possible ways to cope or are impelled to do so from sheer desperation. It is in this context that informal collectives of individuals and civil society organisations came together with a single aim: try to help as many people access timely and appropriate healthcare. ${ }^{7}$ We write from the perspective arising from the experiences of bridging the disconnect between patients and the system during an unprecedented crisis, based on observations and experiences of volunteering for one or more such collectives.

Most of these informal collectives supported health systems through improvised back-end processes. They adopted a multipronged approach covering an array of support initiatives, organised mainly through telephonic coordination for arranging access to medical services. While there are several such collectives across multiple states in India, and the assistance did cover multiple cities, we share some challenges and reflections, specifically in the context of the National Capital Region of Delhi-pooling experiences from involvement of the authors in many of them. These collectives consisted of professionals from multiple backgrounds, such as medical, public health, law, arts and social work who committed their time, energy and often money and materials wholly voluntarily. Patients and families reached the collectives mostly through word of mouth, community networks and the participating volunteers connected with grassroots work.

While some collectives dealt with issues spontaneously and randomly, others had a more systematic approach. This included documenting cases with information such as patient name, age, sex, oxygen saturation level, COVID-19 status, address, phone number, present condition, comorbidities and present requirements. A volunteer then helped the family for their specific 
requirement. Such volunteers tried to work with families throughout their journey of accessing care. The models of assistance included one or more strategies of responding to evolving needs such as finding medical care within hospitals or organising home care, teleconsultations, financial assistance and psychosocial support, as well as, wherever needed, facilitating postdeath services. Most of the cases, especially in the early days of the crisis, reached the collectives at critical stages. The processes of helping not only revealed how further weakened the health system became, but also provided a firsthand account of the harrowing experiences of patients and their families from various social strata. An intricate account of this was shared by authors SC and VP in a BMJ Global Health $\operatorname{blog}^{8}$ and this editorial expands upon some of the broader challenges and responses encountered by the collectives.

\section{CHALLENGES AND RESPONSES}

The overarching challenges faced during this crisis were mostly systemic, where there was a great deficit of supply (service or product availability, medical infrastructure and human resources-both public and private), compared with very high demand. The collectives were challenged in bridging this mismatch while catering to the needs of families from different socioeconomic classes. The response to these challenges was also enhanced by the differing views between the public health community and administration, particularly due to a few protocols that contradicted each other and did not seem to have a scientific basis. ${ }^{9}$ Such situations also prompted the collective to analyse systemic and policy issues and suggest immediate corrective measures. This was done by connecting with the public health and civil society networks, administrators, the legal system, the media and politicians. Building on these experiences, we outline five broad categories that specifically challenged the collectives.

\section{Home-based management}

From the onset of symptoms, families were unsure of what to do considering the lack of adequate guidance and vast amount of misinformation. When symptoms increased, they were unsure of which hospital to turn to or how to do so. As a result, some reached out to volunteers for help. Till mid-May, a confirmed COVID-19 test was required to get admission in a hospital. However, testing was often unavailable or inaccessible, labs were overbooked, it was expensive for many families and there were delays in getting reports. This resulted in patients losing time and eventually resorting to homebased management as they could not access a hospital bed. First, the lack of basic equipment such as oximeters and thermometers made the volunteers improvise ways of organising these through contacting several suppliers in close proximity to the family. Second, home-based care meant finding consistent oxygen supplies through cylinders, refills, concentrators or oxygen cans, all the while checking updates for a hospital bed. Once such equipment was obtained, the lack of awareness on how to operate the equipment led families and volunteers to desperately figure out the methods themselves. The collectives had to routinely engage with alternate existing services or personal contacts to help patients stabilise themselves at home.

It was at this point of home-based management that the starkness of inequity was becoming evident. The patients from lower socioeconomic strata expectedly had less financial stability to access and afford care, lower literacy levels to understand processes and treatment, lack of access to technology including social media (platforms like Twitter became a pseudo helpline for finding resources like beds and oxygen) and less power to use influential contacts for help. The privileged classes, on the contrary, were able to exercise more autonomy and power in accessing timely care during this crisis. ${ }^{8}$ While the collectives aimed to help all individuals regardless of the background, it was challenging yet important to especially cater appropriately to those more marginalised. This included acknowledging a lack of sensitivity and awareness by the larger society to the needs of marginalised communities, requiring skilled negotiations on the collectives' part.

\section{Referral and transportation}

Finding hospital beds (with oxygen, intensive care unit or other critical care services) was a challenge where volunteers had to rely on tech-centric approaches for bed availability. This included using government dashboards that did not reflect real-time availability, making volunteers continuously check the portals as a race against time. Human resources in hospital administrations were inadequate with one nodal officer appointed for an entire hospital (some even catering to more than 1500 patients). These nodal officers were called to check for bed availability; however, during the peak of the cases, many could not respond due to an overburden of calls and other duties.

Volunteers also had to rely on their own social capital, professional networks, social media or public representatives to help find a bed and transport the patient. Government and private ambulances varied with the type of available equipment and services (eg, not all had oxygen), and as cases increased, they quickly became unavailable. The demand for private ambulances even saw instances where transportation costs skyrocketed to more than INR20 000 (US\$275) for less than a $10 \mathrm{~km}$ distanceunaffordable for many families. A few collectives hired SUV cars, converted them into oxygen ambulances by crowd-sourced donations and gave basic medical training to commercial drivers for them to operate oxygen flow, monitor the patient's condition and handle any emergency. However, in addition to these transportation barriers, sometimes the bed was unavailable on reaching the hospital, forcing families and volunteers to desperately find the next available bed. This also depended on 
whether families were able to afford private hospitals, and if not, collectives tried to assist in medical expenses if there was a bed available. The entire routine of accessing hospital admissions almost became cyclical wherein the efforts were often tiring for volunteers, especially in the face of failures in facilitating access.

\section{Plugging in hospital healthcare gaps}

Hospitals across public and private sectors were overwhelmed with cases where existing resources were exhausted beyond capacity. There were SOS calls on social media from hospitals running out of oxygen, for example. In addition, basic and critical care equipment was at times unavailable, forcing the collectives to help locate suppliers who could provide equipment such as oxygen cylinders, concentrators, ventilators and bilevel positive airway pressure machines directly to the treating facilities. This included fundraising to buy equipment for hospitalised families who could not afford it. The lack of adequate health workforce also meant patients and families often required additional teleconsultation, which the collectives tried to provide either through existing services or through personal networks. Another challenge was supporting families that could not get information of the patient's status or could not meet the patient. This involved contacting the nodal officers, negotiating attendant access and/or better care.

The collectives also tried to help caregivers by providing information on accessing drugs prescribed by doctors. As demands rose and regulatory mechanisms failed, emergence of and exploitation by the illicit and counterfeit markets were another challenge, where adhering to legitimate systems and prices was difficult for families while addressing emergency needs. Despite this, a few collectives consciously tried to facilitate an understanding among families on how to obtain quality drugs and supplies through legitimate systems. A few drugs, such as remdesivir, were in short supply and it was difficult to authenticate which supplier was genuine. For plasma, due to the contradictory scientific evidence, some of the collectives decided not to help directly. However, families were in desperate situations; they were unaware of the nuances of plasma use and understood that it was essential for the survival of their near and dear ones. Hence, other collectives provided external links for plasma suppliers on a few occasions. Overall, the collectives were not only challenged in plugging in the system's gaps for tangible essentials but also faced an ethical dilemma of supporting irrational prescriptions and practices.

\section{Using an integrated approach of response}

To elicit timely and adequate emergency ground responses, a few collectives, or individuals associated with them, collaborated with others involved in various sectors such as public health, health rights, law and civil society. The work specifically comprised tackling time-sensitive systemic issues affecting access to patient support and services, by engaging with legal and policy mechanisms of redress. This included interventions in the courts for demanding that the marginalised not be excluded and bed allocations managed in an effective manner among others. Some of them also tried to petition for serious issues requiring immediate redressal, such as oxygen access and overall bed availability.

It is important to note that this integrated approach of linking field experience with systemic interventions helped in responding to acute and immediate concerns. However, a similar effort at a higher level of institutional participation was also crucial. As the collectives worked on the ground to support systems, it was unclear when (and if) published research and recommendations from various institutions and academics were translated into policy. There seemed to be a disconnect between institutions, policymakers and health practitioners, where the lack of consonance between various public health agencies and contradictions by the administration overall impacted the trust of healthcare professionals and the public. Some members of the collectives also worked with others to make policy recommendations and demands for more rational and consonant practice to address this gap.

\section{Managing distress of patients, caregivers and volunteers}

As the crisis worsened, managing the distress of patients, caregivers and volunteers became crucial. Families went through intense periods of grief and trauma, where volunteers were often the first point of contact. Many volunteers were at the receiving end of bad news and had to appropriately prepare themselves mentally to either break the news to families or learn to console and counsel over the phone. Severely affected cases were often referred to trained counsellors within the collectives. Volunteers were communicating with strangers, building a bond, and sometimes when the patient died, the dynamics of the bond changed where families expressed disappointment or sadness in the assisting process. This further affected volunteers where some felt guilt or blame for failing to save the patient. Some volunteers also felt numb and burnt out after dealing with so many cases, and several of them faced difficulties in managing their mental state and well-being.

Many also had to deal with sickness in their own families, friends and relatives, impacting their resilience to continue helping others. Volunteers were constantly encouraged to take timeout if they were feeling overwhelmed. Counselling and therapy options were provided, ensuring safe and non-judgemental respite spaces, as needed.

In addition, it was challenging for many volunteers to deal with distressed individuals from different backgrounds, especially socioeconomic classes where, for example, a few middle-upper-class families presented a sense of entitlement at times, wanting only the best perceived hospitals and doctors and/or additional unnecessary resources. This added significantly towards the stress of the volunteers wanting to assist but not on 
these terms. On the contrary, patients from lower socioeconomic classes had fewer options, and volunteers had to become the proxy social capital for them. All of this presented additional nuanced layers to the challenges in helping individuals who presented with different demands for support.

\section{CONCLUSION}

The extent of suffering during this crisis could have been pre-empted had the system (and leadership) adequately recognised the possibility of future waves. We acknowledge that the collectives functioned with very limited capacity where many cases unfortunately could not result in successful outcomes. Also, it is certain that many needy families could not even reach out to the collectives for help and would have accepted their destiny as it is. However, the efforts to bridge the system with the public enabled some semblance of unity and strength to face the crisis together and try to help where they could. It is also acknowledged that the work of the collectives has been largely urban-centric, although a few smaller towns were also covered. Nevertheless, the wave now shifted to rural areas, ${ }^{10}$ which remains a challenge for the collectives given the lack of basic infrastructure, services and digital divide in fostering connection.

What we can extract from this experience by way of suggestions for system strengthening reinforces recommended frameworks ${ }^{11}$ of a good public health response that depend on principles of providing comprehensive, multitiered, multisectoral and rational care. This includes developing preventive rather than reactive mechanisms and enhancing the necessary components of community information, mobilisation and participation. It highlights the need for an intense and skilled facilitation particularly for vulnerable families to be able to negotiate the system and access care. In addition, it highlights the need to greatly increase human and financial resources and the regulation of the private sector to curb profiteering from the pandemic and reduce out-of-pocket expenditures. Such regulation should also ensure that the hoarding and illicit marketing of essential drugs and supplies have been curbed and the counterfeit market has been cracked effectively. This crisis is also an important reminder that intersectional work needs to involve voices from rural regions much earlier on to prepare them for such shocks. This can only be achieved under the ambit of governments that are willing to engage in meaningful, consultative and transparent participation with diverse stakeholders.

Finally, it invokes trust in the power of the collectives to engage, persevere and find creative ways to overcome the severest of challenges as human beings concerned for other human beings, brought together by compassion and a commitment to social justice. Although the work of the collectives has remained largely invisible, we have all been privileged and enriched by playing our own small parts in these processes. We have the commitment to contribute towards building a system that makes such efforts redundant in the future. However, that requires governments to recognise that efforts such as those of various collectives are only attempting to support and supplement their own, with the intention to alleviate distress.

Acknowledgements We would like to acknowledge and thank every member of the various collectives who have dedicated their time towards helping people in this crisis.

Contributors All authors conceptualised the article. NF, VP and VR wrote the initial draft with revisions and inputs from JS, SC and MM. All authors revised subsequent drafts and approved the final version.

Funding The authors have not declared a specific grant for this research from any funding agency in the public, commercial or not-for-profit sectors.

Disclaimer Views belong solely to the authors and do not necessarily represent the opinions of individuals involved in various collectives, views of any particular collective or views of any affiliated organisation.

Competing interests None declared.

Patient consent for publication Not required.

Provenance and peer review Commissioned; internally peer reviewed.

Data availability statement There are no data in this work.

Open access This is an open access article distributed in accordance with the Creative Commons Attribution Non Commercial (CC BY-NC 4.0) license, which permits others to distribute, remix, adapt, build upon this work non-commercially, and license their derivative works on different terms, provided the original work is properly cited, appropriate credit is given, any changes made indicated, and the use is non-commercial. See: http://creativecommons.org/licenses/by-nc/4.0/.

Author note NF, VP and VR are public health professionals with expertise in the Indian health system. JS, SC and MM are allied professionals supporting public health work in India. All authors were intensively engaged in voluntary informal support during the second wave crisis, including those who were based outside of India.

\section{ORCID iD}

Vandana Prasad http://orcid.org/0000-0003-0640-4965

\section{REFERENCES}

1 Gettleman J, Yasir S, Kumar H. As Covid-19 Devastates India, deaths go Undercounted. New York Times 24 April 2021, 2021. Available: https://www.nytimes.com/2021/04/24/world/asia/indiacoronavirus-deaths.html [Accessed 12 Jun 2021].

2 Biswas S. India's Covid Crisis: The newsroom counting the uncounted deaths 11 May 2021. Available: https://www.bbc.com/ news/world-asia-india-56969086 [Accessed 12 Jun 2021]

3 Sheth A. Non-COVID-19 emergencies in pandemic times. The Hindu 6 May 2020. Available: https://www.thehindu.com/news/ national/tamil-nadu/non-covid-19-emergencies-in-pandemic-times/ article31521897.ece [Accessed 12 Jun 2021].

4 Mathew J. 57\% non-Covid patients cancelled treatment during Mar-Dec 2020: survey. Business Today 5 May 2021. Available: https://www.businesstoday.in/latest/trends/57-non-covid-patientscancelled-treatment-during-mar-dec-2020-survey/story/438345.html [Accessed 12 Jun 2021].

5 Pandey V. India Covid-19: 'No end in sight' as doctors battle second wave. BBC News 7 April 2021. Available: https://www.bbc.com/ news/world-asia-india-56645701 [Accessed 12 Jun 2021].

6 Nadimpally S. Covid-19 has exposed deep cracks in the Indian healthcare system. BMJ Blogs 2021.

7 Menon N, Halder S. Meet the Citizen Groups Addressing COVID-19Induced Inequities. The Wire 9 June 2021. Available: https://thewire. in/health/citizen-groups-covid-19-relief-aid-oxygen-cylindershospitals [Accessed 12 Jun 2021].

8 Chaturvedi S, Prasad V. Blog: coming together to fill the gaps in an inequitable crisis: a story from the second wave of COVID-19 in India. BMJ Global Health Blogs 2021.

9 Kapur M. India is fighting a healthcare crisis of unimaginable proportions with woefully outdated science. Quartz, 2021. Available: 
https://qz.com/india/2003471/india-is-still-using-a-woefullyoutdated-covid-19-treatment-plan/ [Accessed 12 Jun 2021].

10 Pandey V. Coronavirus: The 'unknown' Covid-19 deaths in rural India. BBC News, 2021. Available: https://www.bbc.com/news/av/ world-asia-india-57383131 [Accessed 12 Jun 2021].
11 Prasad V, Sri BS, Gaitonde R. Bridging a false dichotomy in the COVID-19 response: a public health approach to the 'lockdown' debate. BMJ Glob Health 2020;5:e002909. 